\title{
ТОЧНОЕ ИЗМЕРЕНИЕ КОЭФФИЦИЕНТА ОТРАЖЕНИЯ В ИК-ОБЛАСТИ ОТ МИКРОПОВЕРХНОСТЕИ
}

\author{
A. VAINRUB. MIKROPINDADE PEEGELDUSTEGURI TAPNE MOOTMINE INFRAPUNASES \\ PIIRKONNAS
}

A. VAINRUB. PRECISE MEASUREMENT OF IR-REFLECTANCE OF MICROSURFACES

\author{
(Представил Э. Липпмаа)
}

Как известно, определение оптических постоянных кристаллов по их спектрам зеркального отражения требует точного измерения спектральной зависимости абсолютного коэффициента отражения $R(v)\left[{ }^{1}\right]$. Такая задача обычно решается заменой исследуемого кристалла в отражательной приставке спектрометра на эталонное зеркало. Часто, однако, поверхность образца, которая должна быть не менее нескольких десятков м. ${ }^{2}$ для современных ИК-спектрометров, представляет собой мозаику из нескольких кристалликов или естественную грань кристалла с зачерненными дефектными участками поверхности и имеет сложную конфигурацию, что позволяет измерять коэффициент отражения лишь в относительных единицах $R_{\text {отн }}(v)$. В таком случае $R(v)=k R_{\text {отн }}(v)$, где $k$ - переводной множитель, не зависящий от частоты, и переход от спектра $R_{\text {отн }}(v)$ к спектру $R(v)$ представляет собой дополнительную экспериментальную задачу. В настоящей работе мы описываем простой способ ее решения, основанный на измерении $R(v)$ и, следовательно, определении $k$ на частотах ИК-лазера от малых участков поверхности $\left(0,4 \times 0,4 м^{2}\right)$. Достоинством данной методики является возможность выбрать для измерений $R(v)$ наиболее совершенный микроучасток поверхности образца, и существенно повысить тем самым точность последующего определения оптических постоянных, а также возможность проводить измерения для произвольного угла падения света.

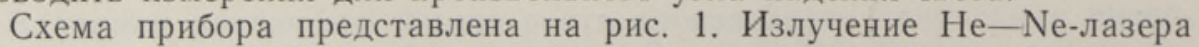
ЛГ-126 1 с $\lambda=3,39$ мкм, промодулированное прерывателем 2 с частотой $150 \Gamma u$, проходит через интерференционный фильтр 3 с полосой пропускания около $\lambda=3,39$ мкм, гарантирующий высокую спектральную чистоту излучения. Параболическое зеркало 4 с $f=200$ мм фокусирует луч лазера на образец 8 , обеспечивая диаметр пятна в фокусе 0,3 мм. Сферическое зеркало 9 с $f=25$ мм фокусирует отраженный свет на чувствительный элемент охлаждаемого жидким азотом Ge-фоторезистора ФСГ-22А 10. Измерительным прибором является селективный микровольтметр В6-4. Образец 8 закреплен на эталонном плоском зеркале 7 , установленном на препаратоводителе, что позволяет производить контролируемые перемещения образца с точностью до 0,1 мм в гори- 


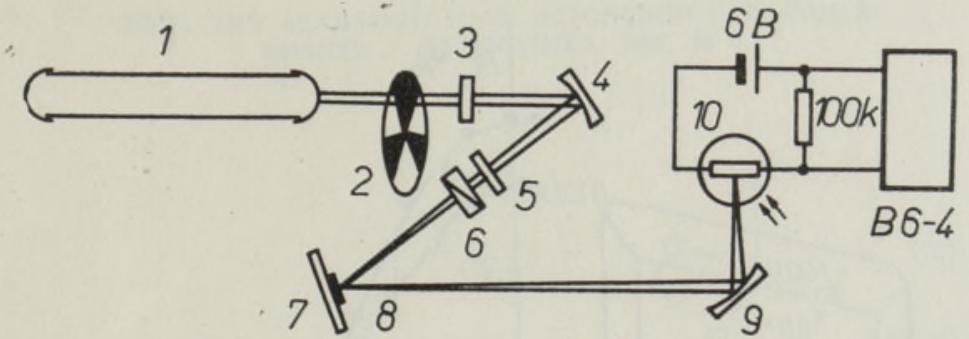

Рис. 1. Схема прибора: 1 - ИК-лазер, 2 - модулятор, 3 - интерференционный фильтр, 4 - параболическое зеркало, 5 - пластинка $\lambda / 4,6$ - дифракционный поляризатор, 7 - эталонное зеркало, установленное на препаратоводителе, 8 - образец, 9 - сферическое зеркало, 10 - фоторезистор.

зонтальном и вертикальном направлениях в плоскости зеркала 7. Измерение отражения образца относительно эталонного зеркала производится последовательным введением в луч образца и зеркала. При исследовании поляризационных зависимостей перед образцом устанавливается пластинка $\lambda / 45$ и поляризатор 6 .

Специальная проверка показала высокую линейность фоторезистора ФСГ-22А как приемника излучения на $\lambda=3,39$ мкм. Поэтому при точной юстировке оптической схемы ошибка измерения определяется главным образом погрешностью измерительного прибора В6-4. Юстировка заключается в установке плоскости образца параллельно плоскости зеркала 7, что легко осуществляется при использовании лазера ЛГ-126, имеющего генерацию в видимой области на длине волны $\lambda=0,63$ мкм. Для этого зеркало 9 выводится из луча, который в данном случае посылается на удаленный на $3-4$ м экран, в луч вводится зеркало 7 , и на экране отмечается положение зайчика. Далее в луч вводится образец и нажимом на уголки образца, приклеенного вязкой вакуумной смазкой к зеркалу 7 , добиваются совпадения зайчика от образца с отметкой на экране. Затем микрометрическими винтами препаратоводителя образещ перемещается и изображения различных его участков рассматриваются в отраженном свете. По резкой форме зайчика находится наиболее совершенный микроучасток, отражение от которого и измеряется.

Прибор использовался для приведения к абсолютному коэффишиенту отражения ИК-спектров комплексов тетрацианохинодиметана (TCNQ), записанных в относительных единицах $\left[{ }^{2,3}\right]$. Точность измерения коэффициента отражения по отношению к эталонному зеркалу по оценке составляла $2 \%$. Изучались также поляризационные зависимости при падении излучения, близком к нормальному. Такие измерения выполнены для триклинного кристалла сложного комплекса с триэтиламмонием TEA-TCNQ 2 (пространственная группа $\overline{P 1}$ ) $\left[{ }^{4}\right]$. В данном случае низкая симметрия кристаллической решетки не определяет направление главных осей тензора диэлектрической проницаемости н, следовательно, поляризацию экстремумов отражения. На рис. 2 показана поляризационная зависимость отражения $R(\varphi)$ для TEA-TCNQ 2 , где $\varphi$ - угол между электрическим вектором $\mathbf{E}$ падающего излучения и кристаллографической осью с, совпадающей с направлением стопок TCNQ. Измерения проведены для наиболее развитой грани естественного роста (100) монокристалла TEA-TCNQ 2 размером $3 \times 0,5 \times 0,2$ мм на близкой к максимуму полосы электронного поглощения частоте $2950 \mathrm{~cm}^{-1}(\lambda=$ $=3,39$ мкм). Максимум $\left(R_{\|}\right)$и минимум $\left(R_{\perp}\right)$ отражения с угловой 


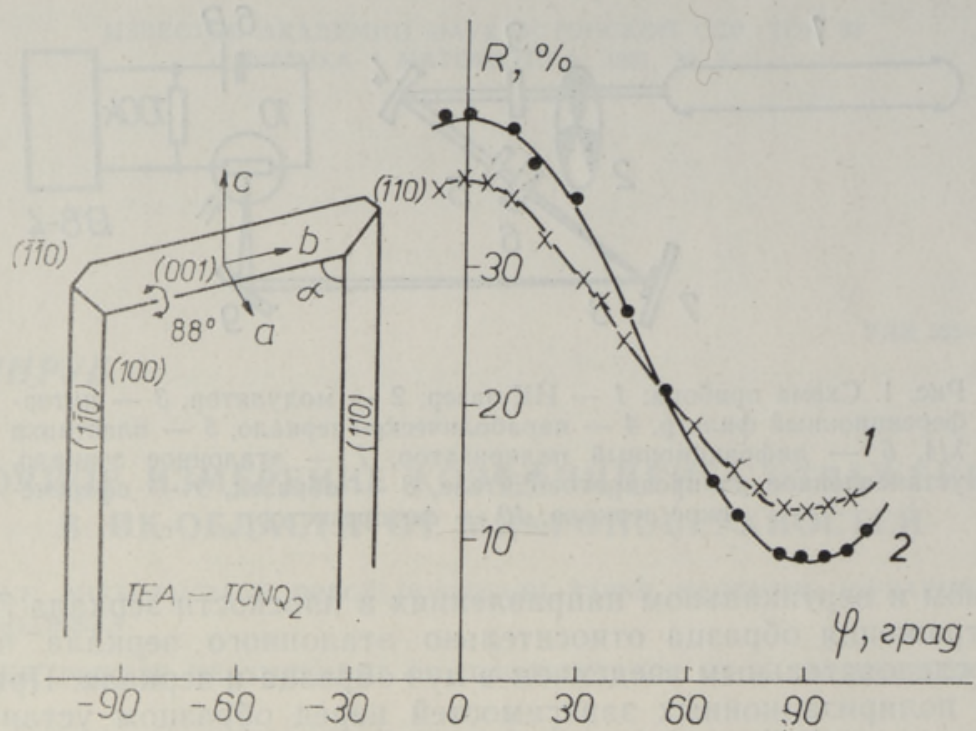

Рис. 2. Зависимость коэффициента отражения от направления поляризации ИК-излучения $\lambda=3,39$ мкм для грани (100) кристалла TEA-TCNQ 2 . Точки - результаты эксперимента, сплошная линия аппроксимация по формуле, приведенной в тексте. Данные 1 и 2 соответствуют различным участкам поверхности кристалла. $\mathrm{Ha}$ вставке - огранка естественного роста кристалла TEA-TCNQ 2 .

точностью не хуже $2^{\circ}$ отвечают поляризациям $\mathbf{E} \| \mathbf{c}$ и $\mathbf{E} \perp \mathbf{c}$ соответственно. Угловая зависимость в пределах ошибки измерений описывается выражением $R(\varphi)=R_{\perp}+\left(R_{\|}-R_{\perp}\right) \cos ^{2} \varphi$. Полученные результаты показывают, что дипольный момент электронного перехода направлен вдоль оси с (стопок TCNQ).

В заключение отметим, что применение в приборе зеркальной оптики и фоторезистора ФСГ-22А с широкой спектральной областью чувствительности позволяет, в принципе, проводить измерения и на других ИК-частотах, используя, например, $\mathrm{CO}_{2}$-лазер.

\section{ЛИТЕ РА Т У Р А}

1. Киз ель В. А., Отражение света, М., «Наука», 1973.

2. Белоусов М. В., В айнруб А. М., Власов а Р. М., Физ. твердого тела, 18, вып. 9, 2637-2641 (1976).

3. Белоусов М. В., В айн ууб А. М., Власов а Р. М., Семкин В. Н., Физ. твердого тела, 20, вып. 1, 107-111 (1978).

4. J a ud, J., Chasseau, D., G a ulti er, J., Hauw, C., C. r. Acad. sci., Ser. C, 278, № 11, 769-771 (1974).

Институт химической и биологической физики Академии наук Эстонской ССР

Поступила в редакцию 11/III 1981 